\title{
HIGH-PRESSURE DIFFRACTION STUDY $\mathrm{OF} \mathrm{Ga}_{1-x} \mathrm{Al}_{x} \mathrm{As}$
}

\author{
W. Paszkowicz, E. Dynowska, Z.R. Żytkiewicz, D. Dobosz \\ Institute of Physics, Polish Academy of Sciences \\ Al. Lotników 32/46, 02-668 Warsaw, Poland \\ AND J.W. OTTO
}

DESY/HASYLAB, Notkestrasse 85, 22603 Hamburg, Germany

The $\mathrm{Ga}_{1-x} \mathrm{Al}_{x} \mathrm{As}$ sample of $x=0.5$ was prepared from a high quality single crystal grown by electroepitaxy on GaAs. The high-pressure diffraction experiments were performed using a diamond anvil cell and a germanium solid state detector. The zinc-blende phase is stable up to about $17.5 \mathrm{GPa}$ on uploading. A high-pressure phase manifests itself at about $17 \mathrm{GPa}, \mathrm{a}$ complete phase change occurs at $18.7 \mathrm{GPa}$. On downloading, the zinc-blende phase reappears at about $10 \mathrm{GPa}$. The powder pattern of the high-pressure phase shows some similarities with the GaAs high pressure phases.

PACS numbers: $62.50 .+\mathrm{p}, 64.30 .+\mathrm{t}, 64.70 . \mathrm{Kw}$

\section{Introduction}

High-pressure phase transitions in binary III-V compounds are subject of extensive X-ray diffraction studies (see, e.g., [1-7]). Rapid advances in such investigations are connected with the progress in the availability and quality of synchrotron radiation sources and data collection systems. To the best of our knowledge, there had been no reported experimental work on phase transitions in III-V solid solutions. An example of such solution is $\mathrm{Ga}_{1-x} \mathrm{Al}{ }_{x} \mathrm{As}$ being an important semiconductor material with numerous applications. The high-pressure transitions are different for GaAs and AlAs. Therefore, it is interesting to determine whether and in what range the solid solution conserves the high-pressure structure types of its binary end members. The zinc-blende GaAs transforms to the orthorhombic GaAs-II type [2] (see also data of Ref. [1]). The transition pressure has been concluded to be $12( \pm 1.5) \mathrm{GPa}[8]$. This high-pressure structure type is specific for GaAs. With a further increase in pressure, there are other phase transitions in GaAs [2]. The zinc-blende AlAs transforms to the hexagonal NiAs type. This transition has been found experimentally [3] (transition pressure $7 \pm 5 \mathrm{GPa}$ ) and supported by $a b$ initio calculations [6]. The NiAs type is known for another III-V high-pressure phase, AlP [9] and for a larger number of II-VI compounds [6]. 


\section{Experimental}

The $\mathrm{Ga}_{1-x} \mathrm{Al}_{x}$ As sample, with $x=0.5$, was prepared from a high quality single crystal grown by electroepitaxy on a (100) oriented GaAs substrate. The substrate was dissolved using preferential etching and then the finely ground crystal was mixed with $\mathrm{NaCl}$ treated as a pressure transmitting medium and as a pressure marker. The experiments were performed at HASYLAB on F3 line in energy-dispersive mode using a diamond anvil cell and a germanium solid state detector. The applied diffraction angle was $\theta=5.2374^{\circ}$.

\section{Results}

The pressure-volume dependence (cf. Fig. 1) allowed us to obtain the bulk modulus of the zinc-blende phase which is stable up to about $17.5 \mathrm{GPa}$ on uploading. The bulk modulus value and its first derivative $(72.5 \mathrm{GPa}$ and 4.2 , respectively), calculated in this work by fitting the Birch-Murnaghan equation [10], are in reasonable agreement with interpolated literature data [11] for $\mathrm{Ga}_{1-x} \mathrm{Al}_{x} \mathrm{As}$ (Table).

New peaks belonging to a high-pressure phase manifest themselves at about $17 \mathrm{GPa}$. Further uploading leads to a complete phase change observed at $18.7 \mathrm{GPa}$, where the zinc-blende-type peaks disappear. Downloading starting from $18.7 \mathrm{GPa}$ causes first an enhancement of some weak peaks already visible at $18.7 \mathrm{GPa}$. The zinc-blende phase reappears at about $10 \mathrm{GPa}$, so the transition may be concluded to occur at about $13.5 \mathrm{GPa}$ with hysteresis ranging from 10 to $17 \mathrm{GPa}$. The transition pressure is closer to the GaAs case while the hysteresis is intermediate

TABLE

The bulk modulus value for $\mathrm{Ga}_{1-x} \mathrm{Al}_{x} \mathrm{As}, x=0.5$, calculated by fitting the Birch-Murnaghan equation compared to the literature values for zinc-blende-type $\mathrm{Ga}_{1-x} \mathrm{Al}_{x} \mathrm{As}, \mathrm{GaAs}$ and AlAs. Starred is the value obtained from the linear dependence $B_{0}(x)[11]$.

\begin{tabular}{|c|c|c|c|}
\hline Composition & $\begin{array}{c}\text { Bulk } \\
\text { modulus } \\
B_{0}[\mathrm{GPa}]\end{array}$ & $\begin{array}{c}\text { First pressure } \\
\text { derivative of the } \\
\text { bulk modulus } \\
\mathrm{d} B_{0} / \mathrm{d} p\end{array}$ & Reference \\
\hline GaAs & 75.5 & 4.49 & $\begin{array}{l}{[11,12]} \\
{[12]}\end{array}$ \\
\hline $\mathrm{Ga}_{0.5} \mathrm{Al}_{0.5} \mathrm{As}$ & $\begin{array}{l}76.8^{*} \\
72.5\end{array}$ & 4.2 & $\begin{array}{l}{[11]} \\
\text { this work }\end{array}$ \\
\hline AlAs & $\begin{array}{c}78.1 \\
74(4)^{\dagger} \\
74.2\end{array}$ & $\begin{array}{c}5(1)^{\dagger} \\
4.3\end{array}$ & $\begin{array}{l}{[11]} \\
\text { derived in [6] from data of }[4] \\
\text { a verage of theoretical values } \\
\text { collected in }[6]\end{array}$ \\
\hline
\end{tabular}

$t^{\dagger}$ numbers in parentheses refer to the error values. 


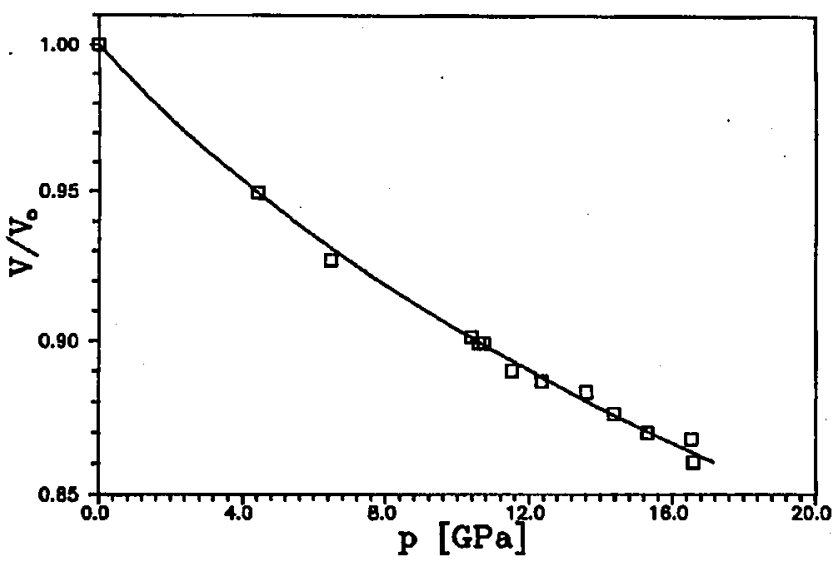

Fig. 1. Compression of zinc-blende type $\mathrm{Ga}_{0.5} \mathrm{Al}_{0.5} \mathrm{As}$.

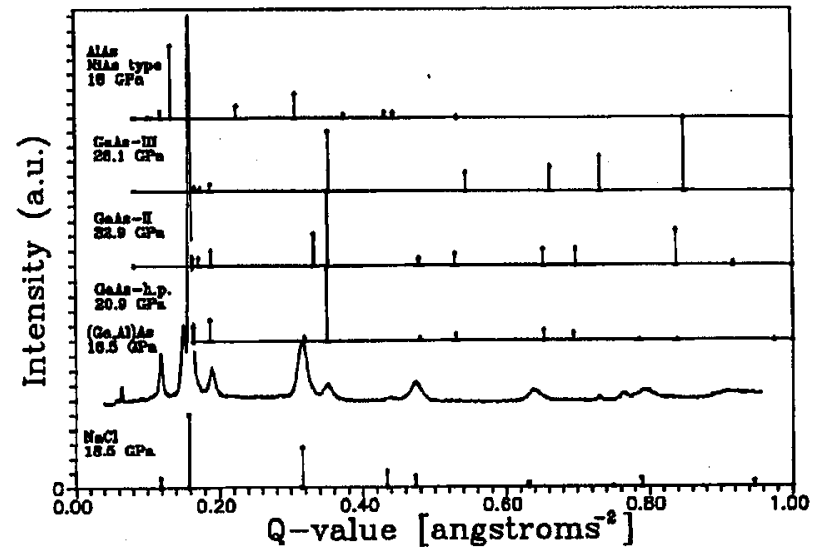

Fig. 2. A comparison of the high-pressure powder pattern for $\mathrm{Ga}_{0.5} \mathrm{Al}_{0.5}$ As with literature data for GaAs and AlAs. The following powder patterns are included: in the form of bars representing peak positions and intensities: AlAs of NiAs type at $18 \mathrm{GPa}$ [3], GaAs-III at 28.1 GPa [2], GaAs-II at $22.9 \mathrm{GPa}$ [2], high-pressure GaAs at $20.9 \mathrm{GPa}$ [1]; powder pattern of $\mathrm{Ga}_{0.5} \mathrm{Al}_{0.5}$ As obtained in this work at $18.7 \mathrm{GPa}$; peak positions and intensities for $\mathrm{NaCl}$ pressure marker; the positions are derived from the $\mathrm{NaCl}$ equation of state, the intensities are those of the ICDD standard at ambient conditions.

between GaAs and AlAs cases. The powder diagram of the high-pressure phase is compared with the literature data for binary GaAs and AlAs in Fig. 2. It shows some similarities with $\mathrm{GaAs}$ literature data being markedly different from the NiAs type observed for AlAs. A possible overlap with $\mathrm{NaCl}$ lines makes the analysis of the new high-pressure phase difficult and indicates that using another pressure marker should be considered in more systematic investigations. 


\section{Acknowledgments}

The authors are indebted to dr Thomas Wroblewski (DESY/HASYLAB) for fruitful discussions. Partial supports of the Committee for Scientific Research (Poland) (grant No. PB 101/P3/93/05 (2P30208305)) and Deutsche Forschungsgemainschaft are gratefully acknowledged.

\section{References}

[1] M. Baublitz, Jr, A.L. Ruoff, J. Appl. Phys. 53, 6179 (1982).

[2] S.T. Weir, Y.K. Vohra, C.A. Vanderborgh, A.L. Ruoff, Phys. Rev. B 39, 1280 (1989).

[3] R.G. Greene, H. Luo, T. Li, A.L. Ruoff, Phys. Rev. B 72, 2045 (1994).

[4] M.I. McMahon, R.J. Nelmes, J. Phys. Chem. Solids 56, 485 (1995).

[5] J. Crain, G.J. Ackland, S.J. Clark, Rep. Prog. Phys. 58, 705 (1995).

[6] G.C. Liu, Z.W. Lu, B.M. Klein, Phys. Rev. B 51, 5678 (1995).

[7] H. Luo, K. Ghandehari, R.G. Greene, A.L. Ruoff, S.S. Trail, F.J. DiSalvo, Phys. Rev. B 52, 7058 (1995).

[8] J.M. Besson, J.P. Itié, A. Polian, G. Weil, J.L. Mansot, J. Gonzalez, Phys. Rev. B 44, 4214 (1991).

[9] R.G. Greene, H. Luo, A.L. Ruoff, J. Appl. Phys. 76, 7296 (1994).

[10] R.M. Hazen, L.W. Finger, Comparative Crystal Chemistry, John Wiley \& Sons, Chichester 1982.

[11] Landolt-Börnstein, Numerical Data and Functional Relationships in Science and Technology, Group III, Vol. III/22a, Springer Verlag, Berlin 1986, p. 138.

[12] J.C. Brice, in: Properties of Gallium Arsenide, 2nd ed., INSPEC, London, New York 1990, p. 113. 